\title{
Água e desenvolvimento rural
}

\author{
ALDO DA C. REBOUCAS
}

"A água é um recurso finito e fator competitivo do mercado. Seu uso eficiente torna-se mais importante que ostentar sua abundância”.

A VIDA RURAL foi muito romantizada durante milênios, especialmente no Ocidente. O primeiro grande poema grego - Os trabalhos e os dias - de Hesíodo, século VI a.C., romantizou a vida no campo. O mesmo fez o poema romano, as Geórgicas de Virgílio, do século I a.C.

Entretanto, a vida no campo sempre ofereceu menores oportunidades de desenvolvimento ao indivíduo, sempre foi muito árdua, compulsória e coerciva. A menor ação compulsória e coerciva da vida urbana explica, certamente, por que, por milênios, o sonho das pessoas do campo foi o de mudar para a cidade, mesmo quando esta não lhes oferece emprego nem habitação. Regra geral, os mais sabidos migram, enquanto os menos sabidos ficam.

A vida menos coercitiva na cidade possibilitou a ascensão de profissionais liberais, artistas, comerciantes, artesãos altamente habilidosos em suas corporações de ofícios e a formação de uma aristocracia burguesa. Estes atrativos deram suporte ao êxodo rural que ocorreu na Europa, principalmente, nos dois últimos séculos. Porém, por trás desses grupos de indivíduos bem sucedidos, a falta de uma atitude compulsória e coerciva nas cidades do mundo em geral favoreceu o desenvolvimento de anomias moral e social que deram suporte à prostituição e ao banditismo, tornando a vida na cidade um pesadelo e afetando a tranqüilidade da vida no campo.

Assim, tem-se uma imagem idílica da vida na cidade, tão irreal quanto a imagem romantizada da vida no campo. Nestes cenários a disponibilidade do recurso hídrico tornou-se um fator competitivo do mercado, sendo cada vez mais importante saber usar a gota d'água disponível do que ostentar sua abundância.

\section{Água no mundo: abundância, desperdício, escassez}

Considerando que as rochas mais antigas formadas em ambiente aquático - até agora datadas - têm idade da ordem de 3,8 bilhões de anos, pode-se supor que a água existe na Terra na forma líquida, pelo menos, desde então. Por sua vez, o planeta Terra é o único corpo do Sistema Solar, até agora conhecido, onde a água existe, ao mesmo tempo, nos três estados físicos fundamentais: sólida ou gelo nas calotas polares e geleiras; líquida nos oceanos e formando os corpos de água 
doce (menos de $1000 \mathrm{mg} / \mathrm{L}$ de sólidos totais dissolvidos) dos continentes - rios, lagos, umidade do solo e o manancial subterrâneo; vapor de água na atmosfera.

A energia solar que incide sobre a superfície da Terra e a transpiração da biomassa vegetal e animal, inclusive o homem, transformam em vapor uma parcela importante da água que forma os oceanos, as calotas polares, a umidade do solo e até as águas subterrâneas que são acumuladas a profundidades inferiores a um metro. Este vapor de água sobe à atmosfera, onde esfria progressivamente e se condensa para dar origem às nuvens. As massas de água atmosférica assim formadas são atraídas pela gravidade e voltam a cair na Terra, principalmente na forma de chuva, neblina e neve. Portanto, o gigantesco mecanismo de renovação das águas da Terra é movido pela energia solar (evaporação) e pela força gravitacional (precipitação) há bilhões de anos.

Nesse quadro, uma parcela da água que cai nas porções continentais do mundo forma as enxurradas que são drenadas pelos rios, cuja descarga total média de longo período de água doce é da ordem de $43 \mathrm{mil} \mathrm{km}^{3} /$ ano. Outra parcela infiltra-se no solo para reconstituir a sua umidade, a qual dá suporte ao desenvolvimento da cobertura vegetal, natural ou cultivada. Os processos fotossintéticos transformam a energia solar (luz) em energia química, na forma de carboidratos, base da alimentação dos seres superiores, inclusive o homem.

O excedente da parcela infiltrada no solo vai alimentar os estoques de água que ocorrem no seu subsolo, cujos fluxos podem desaguar nos rios que compõem bacias hidrográficas, durante os períodos de estiagem ou sem chuvas.

Desta forma, quando se tem um curso d'água perene, ou seja, que nunca seca, significa que os estoques de água formados no subsolo da sua bacia hidrográfica são suficientemente importantes para alimentar os fluxos de base dos seus rios durante todo o período de estiagem ou sem chuvas. Assim, a descarga de base dos rios do mundo, da ordem de $13 \mathrm{mil} \mathrm{km}^{3} / \mathrm{ano}$, corresponde à contribuição dos fluxos subterrâneos às suas vazões totais médias de longo período.

Portanto, a captação desordenada da água subterrânea de uma determinada bacia hidrográfica poderá engendrar a redução dos fluxos de base dos seus rios, cujas conseqüências sociais, ambientais e econômicas poderão ser muito sérias (figura 1).

Por sua vez, a água não é como os demais recursos naturais da Terra, nem somente uma matéria-prima. Ela é primordialmente um bem ambiental e pode se tornar um bem econômico. É a única matéria-prima ambiental cuja utilização tem um efeito de retorno sobre o manancial utilizado. Desta forma, a gestão dos recursos hídricos - água de chuva, rios, subterrâneas e de reuso não-potável no meio urbano, nas indústrias e na agricultura, principalmente - deve considerar o uso cada vez mais eficiente da água disponível, ou seja, a obtenção de cada vez mais benefícios com o uso de cada vez menos água e proteção da sua qualidade. 


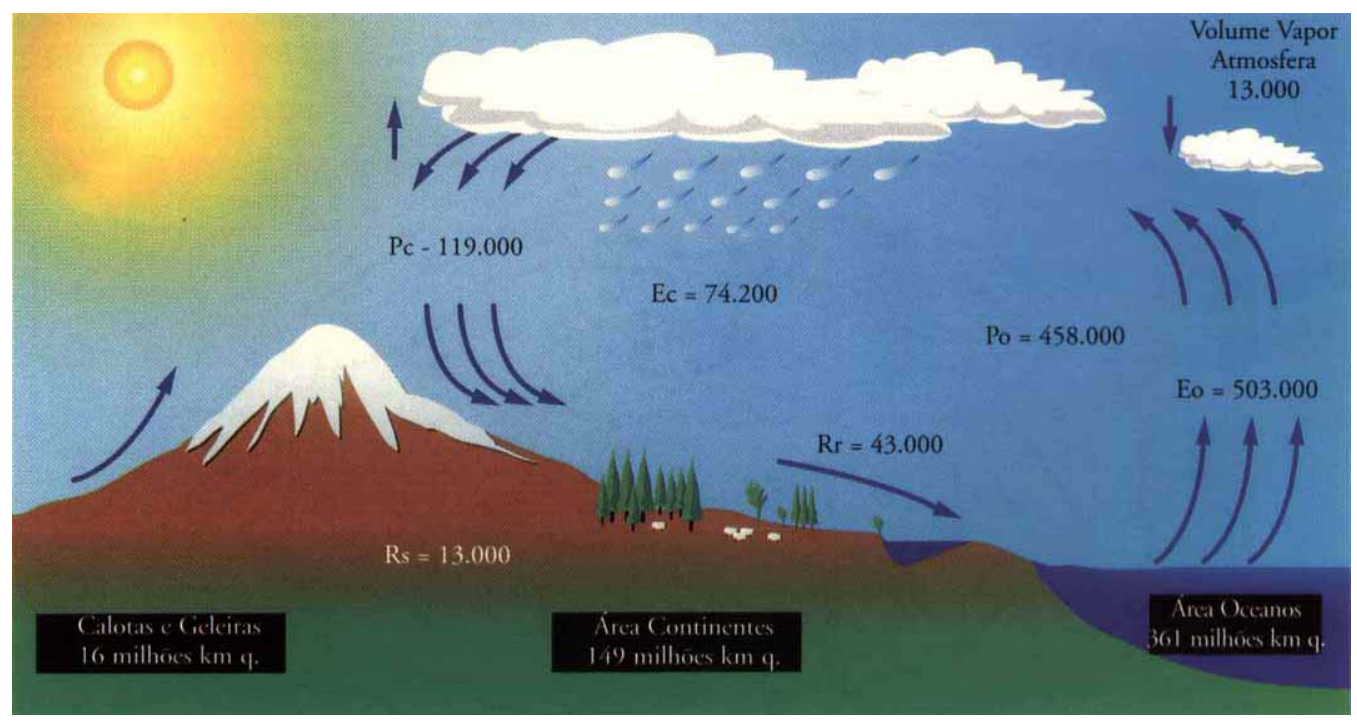

Figura 1. O gigantesco ciclo das águas da Terra.

Fonte: Rebouças et al., 1999.

No primeiro caso, entram em consideração as reservas e os respectivos potenciais de renovação das quantidades dos recursos naturais. No segundo, devese considerar a capacidade de regeneração das águas servidas - uso doméstico, industrial ou agrícola, principalmente - que retornam ao manancial. Entretanto, estes recursos hídricos têm uma capacidade de regeneração limitada. Quando os limites da quantidade ou da qualidade são ultrapassados pela intervenção humana, pode se caracterizar uma situação de desequilíbrio, escassez ou degradação da qualidade da água disponível, tal como ocorre hoje no Brasil, em níveis nunca imaginados.

Enfim, a água é uma matéria-prima de difícil valoração como "ativo natural" por ser muito grande a sua utilidade e não haver substituto para a maioria de seus usos. Além disso, os seus valores de mercado são geralmente muito baixos, mesmo se os produtos finais dela derivados alcancem altos valores de venda, tal como os produtos industriais. Desta forma, a maior parte da água utilizada em todos os países do mundo ainda é, com freqüência, considerada um bem livre, isto é, seu valor financeiro implícito não faz parte das planilhas de custos dos projetos de abastecimento público, industrial ou agrícola.

Como resultado, discute-se mais sobre as águas da natureza, sobre sua repartição, suas funções como agente sócio-econômico e como componente ambiental, do que sobre a necessidade do seu uso ser cada vez mais eficiente, ou seja, de se conseguir cada vez mais produtividade e conforto, utilizando cada vez menos água. 
O mau uso predominante das águas no mundo em geral, e no Brasil em particular, vem engendrando a sua escassez relativa e a degradação da qualidade da água disponível em níveis jamais imaginados, de tal forma que as clássicas expressões "água é vida”, “água elixir da vida” e tantas outras formas de exprimir sua importância vital se tornam praticamente obsoletas.

No novo paradigma da globalização, porém, a disponibilidade de água doce torna-se cada vez mais um negócio e fator econômico competitivo do mercado. A falta de consideração ou de conhecimento desta perspectiva vem colocando a América Latina, em geral, e o Brasil, em particular - cujos potenciais de água doce são os maiores do mundo - na vala comum dos países desenvolvidos e periféricos que, efetivamente, já enfrentam problemas de escassez de água.

\section{Uso eficiente da gota d'água disponível: alternativa mais barata e viável}

Os registros geológicos indicam que, há pelo menos um milhão de anos, a quantidade da água da Terra é praticamente constante. Isto não significa, todavia, que os volumes de água contidos nos seus diferentes reservatórios - geleiras, oceanos, rios, lagos e no subsolo - não possam ter variado durante este período.

Basta lembrar que durante o último grande período glacial ocorrido na Terra entre 100 mil e 10 mil anos, os níveis dos oceanos baixaram cerca de $130 \mathrm{~m}$. Este processo resultou da transferência de cerca de 47 milhões $\mathrm{km}^{3}$ de água dos oceanos para os continentes, onde se formou a mais extensa capa de gelo. Esta quantidade de água doce é maior do que a soma dos volumes estocados atualmente na Terra - calotas polares e geleiras (29 milhões $\left.\mathrm{km}^{3}\right)$, águas subterrâneas doces (10 milhões $\mathrm{km}^{3}$ ) e nos rios, lagos e pantanais (127 mil km³).

Por sua vez, enquanto a população atual do mundo (seis bilhões de habitantes) duplicou na última década, a demanda total de água cresceu seis vezes - uso doméstico, industrial e agrícola, principalmente - segundo dados das Nações Unidas (2000). Este processo agravou sobremaneira os problemas engendrados pela falta de sintonia entre a distribuição das águas na Terra e a sua população. Desta forma, a alternativa mais barata e viável para abastecer a crescente população mundial é aprender, como já referido, a usar a água disponível de forma cada vez mais eficiente. Vale salientar que a demanda de água no mundo aumenta mais rapidamente do que a população, sob a pressão das mudanças dos hábitos de higiene e da necessidade de se alcançar uma produtividade cada vez maior de alimentos e de produtos industriais, principalmente.

Assim, considerando-se que as demandas atuais de água da população Mundial (seis bilhões de habitantes) - uso doméstico, industrial e agrícola - representam cerca de $11 \%$ das descargas totais médias de longo período dos seus rios, pode-se dizer que, em escala global, não há falta d'água na Terra. 
Entretanto, aos problemas que são causados pela distribuição muito irregular destes potenciais de água doce no mundo - tanto no espaço quanto no tempo vêm se somar os decorrentes do fato de os desperdícios e a degradação da sua qualidade terem atingido níveis nunca imaginados. Como conseqüência, poderá faltar água limpa de beber nas torneiras, tanto nas cidades quanto no meio rural.

\section{Como e por quem é usada a água doce da Terra}

A idéia de uma Terra coberta de água em sua maior extensão remonta aos tempos primitivos. Entretanto, a sua visão é muito recente à medida que o planeta Terra só foi visto do espaço, pela primeira vez, na década de 60 , pelos primeiros astronautas. Esta visão foi de uma bola azul e branca que brilhava na escuridão do Universo, o que lhe valeu a denominação, desde então, de planeta Água.

Nesse quadro a água salgada da Terra, que forma os seus oceanos e mares, representa 97,5\% do volume total estimado de 1.386 milhões $\mathrm{km}^{3}$. Por sua vez, a água doce - teor de sólidos totais dissolvidos (STD) inferior a $1000 \mathrm{mg} / \mathrm{L}$ - é de apenas $2,5 \%$ deste total (figura 2 ).

Entretanto, o maior volume de água líquida da Terra - acessível aos meios técnicos e financeiros disponíveis - encontra-se escondido no seu subsolo (10 milhões $\mathrm{km}^{3}$ ). Estima-se que $13 \mathrm{mil} \mathrm{km}^{3}$ /ano é de água doce participante do ciclo hidrológico, o qual vem sendo extraído por cerca de 300 milhões de poços que irrigam cerca de 100 milhões de hectares e abastecem mais de metade da população mundial (Unesco, 1998).

Pelo fato de a água subterrânea ocorrer sob uma camada de material filtrante não-saturado ou relativamente menos permeável (confinante), este manancial encontra-se, comparativamente, melhor protegido dos agentes de poluição que afetam rapidamente a qualidade da água dos rios. Como resultado, a água subterrânea é, regra geral, naturalmente potável, característica fundamental que possibilita a sua utilização pelas empresas de água engarrafada. Além disso, a água subterrânea pode ser captada no próprio terreno do condomínio residencial, da indústria ou do perímetro irrigado. Assim, o seu uso para abastecimento humano torna-se mais barato, se comparado com a captação e tratamento das águas de um rio ou de outro manancial de superfície. Não obstante, a sua utilização não pode ser vista como panacéia, ou seja, uma solução para todos os problemas de abastecimento.

A captação da água subterrânea - fontes, galerias ou poços - deverá ser controlada pelo poder federal, estadual ou municipal. Além disso, é necessário considerar que uma obra de captação mal construída, operada ou abandonada, pode se transformar em foco de contaminação do manancial subterrâneo, irreversível no curto e médio prazos. Além disso, a extração descontrolada da água subterrânea de uma bacia hidrográfica poderá desequilibrar o seu balanço hidrológico. 
Portanto, a utilização da água subterrânea que ocorre numa bacia hidrográfica qualquer, deverá ser avaliada como uma das alternativas de abastecimento das demandas de água potável, principalmente numa visão de planejamento e gestão integrada das águas dos rios e de reuso da água tratada não-potável, principalmente.

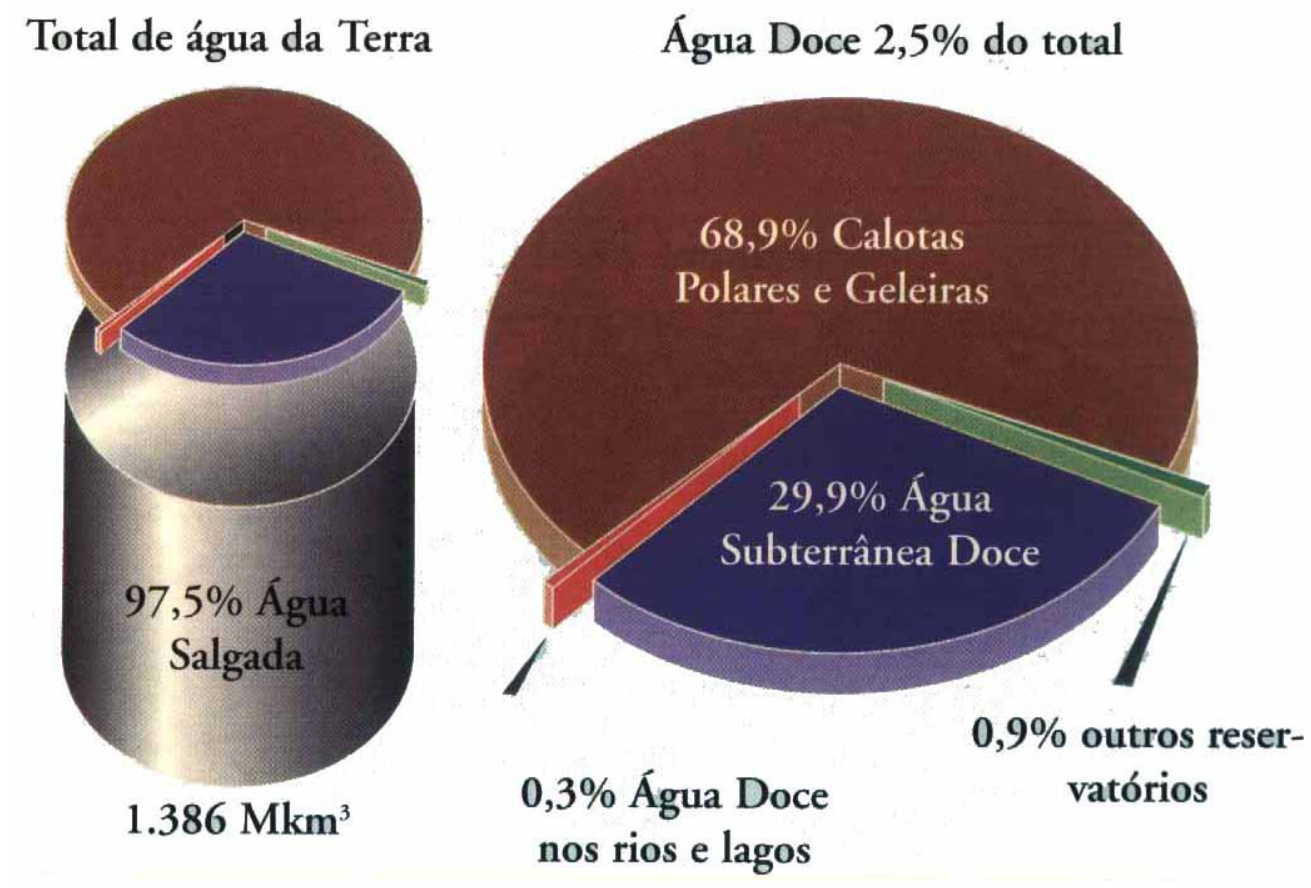

Figura 2. Os volumes de água da Terra

Fonte: Rebouças et al., 1999.

O alcance econômico da utilização das águas subterrâneas naturalmente realimentadas pelas infiltrações periódicas de parcela das precipitações que ocorrem no meio rural é bem ilustrado pelos elementos apresentados na figura 3.

Todavia, a falta de conhecimentos básicos sobre as condições de ocorrência e utilização do manancial de água subterrânea vem transformando a sua utilização, no Brasil, num resultado de loteria. Por sua vez, o caráter mais fotogênico das obras de captação e tratamento das águas dos rios gera maior prestígio aos políticos e aos tomadores de decisão.

Como corolário, no mundo em geral, e no Brasil em particular, a $1^{\mathrm{a}}$ Conferência Mundial da Água, realizada em Mar Del Plata pelas Nações Unidas em 1977, induziu a um grande desenvolvimento das obras de captação e tratamento das águas dos rios, como forma de se reduzir o déficit de abastecimento público. Neste período, no Brasil, houve um acentuado desenvolvimento da engenharia sanitária, sem que tenha ocorrido, todavia, uma sensível melhoria dos quadros sanitários nas cidades. 


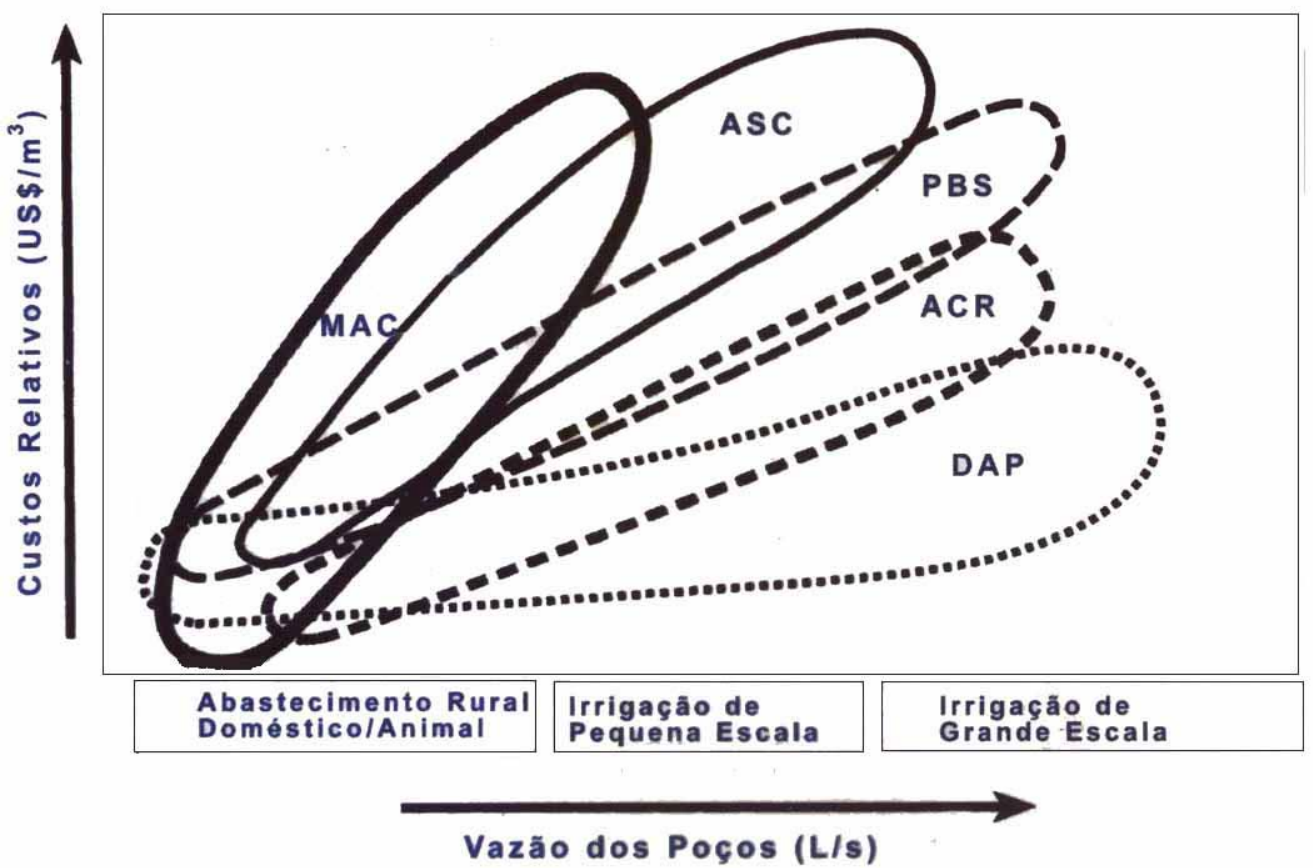

DAP Depósito aluviais principais PBS Pequenas bacias sedimentares ASC Aqüíferos sedimentares consolidados ACR Aqüíferos calcários recentes MAC Manto alteração cristalino

Figura 3. Alcances econômicos da utilização da água subterrânea

Fonte: World Bank, 2000

A demanda total de água no mundo é de apenas cerca de $11 \%$ da vazão média dos rios, $70 \%$ utilizados pelas atividades agrícolas, $20 \%$ pelas industrias e $10 \%$ referentes à demanda do consumo doméstico e uso consumptivo municipal (figura 4).

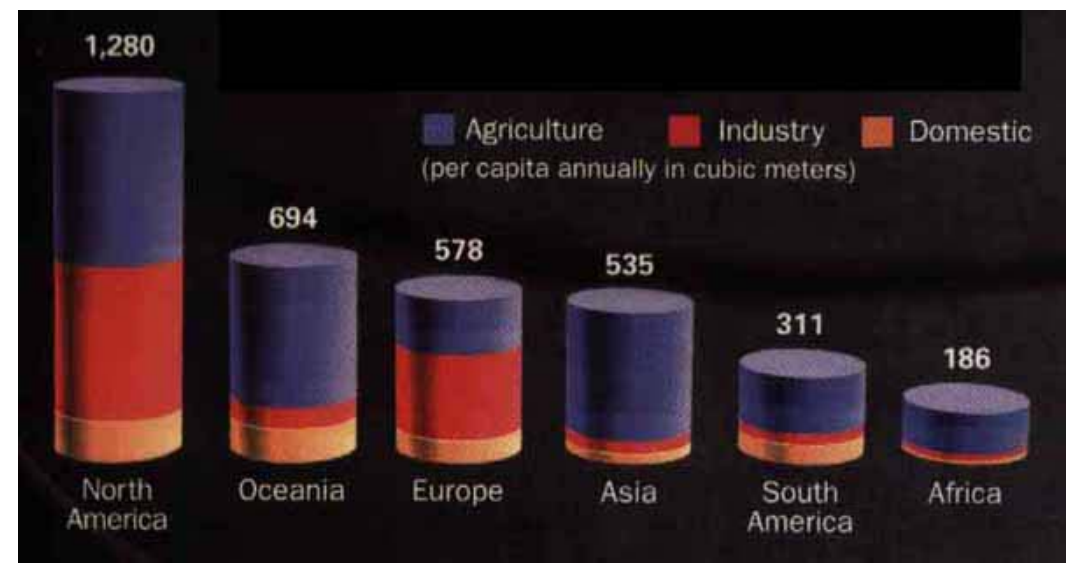

Figura 4. Como e por quem a água doce do mundo é utilizada Fonte: National Geographic, 2001. 
A irrigação é o setor que mais consome água mundialmente e o menos eficiente, ficando o valor médio mundial das perdas entre 50 e 70\% (FAO, 1998). No Brasil, dos quase três milhões de hectares irrigados, sobre mais de 95\% utilizamse os métodos menos eficientes: espalhamento superficial, pivô central e aspersão convencional (Telles, 1999).

Desta forma, a crise atual de abastecimento de água resulta fundamentalmente da má distribuição dos potenciais de água doce disponíveis, a qual vem sendo sensivelmente agravada pelo crescimento desordenado das demandas locais e, sobretudo, pelo fato de a degradação da sua qualidade ter atingido níveis não previstos, tanto no meio urbano quanto no rural.

No Brasil, o meio rural vem sofrendo severamente os impactos das atividades desenvolvidas tradicionalmente nas cidades, à medida que são lançados cerca de 90\% dos esgotos domésticos não-tratados nos rios, os quais degradam a qualidade das águas que fluem por centenas de quilômetros rio abaixo.

\section{Água e desenvolvimento rural no Brasil}

Os descobridores chegaram ao litoral úmido do Brasil e encontraram uma terra rica de rios que nunca secam e uma exuberante cobertura vegetal. Além disso, a idéia de que poderia haver tesouros em metais e pedras preciosas nas grandes extensões de terras habitadas por poucos índios deu suporte ao modelo extrativista implantado pelo colonizador, altamente predador de gente e de recursos naturais.

A visão destes cenários de abundância levou Pero Vaz de Caminha a reportar: “Andamos por ai vendo a ribeira, a qual é de muita água e muito boa (...) Águas são muitas, infindas. E, em tal maneira a terra é graciosa, que querendo aproveitar dar-se-á nela tudo, por bem das águas que tem”.

Entretanto, na perspectiva do mercado global atual, torna-se mais importante saber usar a água disponível - de chuva, rios, subterrânea e de reuso, principalmente - do que ostentar sua abundância. Assim é que o mercado global remunera de forma ótima a atividade agrícola cujo consumo de água é de até $5 \mathrm{mil} \mathrm{m}^{3} /$ ha/ano. O consumo entre $5 \mathrm{mil} \mathrm{e} 10 \mathrm{mil} \mathrm{m}^{3} / \mathrm{ha}$ /ano é considerado razoável e acima de $10 \mathrm{mil} \mathrm{m}^{3} / \mathrm{ha} /$ ano é considerado crítico. Mais importante ainda é que os agri-cultores já começam a levar em conta os parâmetros ditados pelo mercado, tanto sobre a necessidade de utilização dos métodos cada vez mais eficientes quanto da seleção das culturas que apresentam melhores preços no mercado.

A mesa farta da população urbana do mundo, em geral, e do Brasil em particular - onde já vive e trabalha cerca de $81 \%$ da sua população (IBGE, 2000) depende fundamentalmente da produtividade das atividades rurais que são desenvolvidas por uma parcela decrescente da população. Entretanto, a falta de políticas públicas que dêem prioridade aos interesses da sociedade em geral, em detrimento 
dos grupos que participam da "política de bastidores", é a principal responsável pela baixa qualidade de vida da população que vive e trabalha no meio rural e o seu conseqüente êxodo para as cidades.

As condições ainda dominantes de uso e ocupação no meio rural no Brasil são muito primitivas. Nesse quadro, salvo raras e honrosas exceções, os meios e os métodos de produção ainda continuam ostentando as formas extrativistas características do período colonial. Desta forma, a crescente produtividade agropecuária ostentada pelo Brasil - um dos maiores rebanhos de bovinos do mundo e uma produção de grãos estimada em 97 milhões/ton para o ano 2001 - ainda vem sendo proporcionada, em sua maior parte, pela expansão da fronteira agrícola. Em outras palavras, essa crescente produtividade não reflete fundamentalmente um desenvolvimento tecnológico do setor.

\section{Transformação demográfica e crise da água}

Quando o nosso primitivo ancestral se assentou no chão, há cerca de 10 mil anos - ao domesticar animais e cultivar seus alimentos - deu início às transformações demográficas que fazem com que mais de $90 \%$ das populações dos países desenvolvidos e cerca de 75\% daquelas dos países emergentes e subdesenvolvidos atualmente vivam e trabalhem nas cidades. Estas transformações ocorreram no mundo muito lentamente, durante milhares de anos, e foram sobretudo intensas na Europa nos dois últimos séculos.

Entretanto, no Brasil, este processo ocorreu durante a segunda metade do século passado. Basta considerar que os dados do censo demográfico de 1940 indicam que, naquela época, cerca de $69 \%$ da população brasileira ainda vivia no campo, contra menos de 19\% no censo de 2000 (figura 5).

Portanto, a transformação demográfica ocorrida no Brasil não tem precedentes na história da humanidade, e teve por corolário o crescimento desordenado das demandas de água para abastecimento da população que vive e trabalha nas nossas cidades. Além disso, continuou-se no modelo - iniciado pelos romanos em 312 a.C. com a construção dos seus famosos aquadutos - de se buscar água cada vez mais distante como única alternativa para aumentar a sua oferta nas cidades. Até agora, pouco ou quase nada foi feito para se lograr um uso cada vez mais eficiente da água disponível nas nossas cidades. Em outras palavras, muito pouca tem sido a preocupação com a baixa eficiência das empresas de abastecimento, cujas perdas totais de água tratada, cloretada e até fluoretada que é injetada na rede de distribuição variam entre 30 e $60 \%$, e com os grandes desperdícios ostentados pelos usuários, tanto domésticos quanto industrias e principalmente na agricultura.

O desenvolvimento industrial e agrícola que ocorreu no Brasil a partir da década de 40 tornou o tratamento da água - segundo o modelo iniciado na Europa na segunda metade do século XIX - cada vez mais complexo, pouco eficiente 
e fora do alcance financeiro de uma parcela crescente da população das cidades. Desta forma, embora possa haver água em quantidade suficiente no mundo, no país, no estado, no município, certamente poderá faltar água nas torneiras, tendo em vista a falta de dinheiro da maioria da população que vive e trabalha nas cidades, para pagar a conta mensal de consumo d'água.

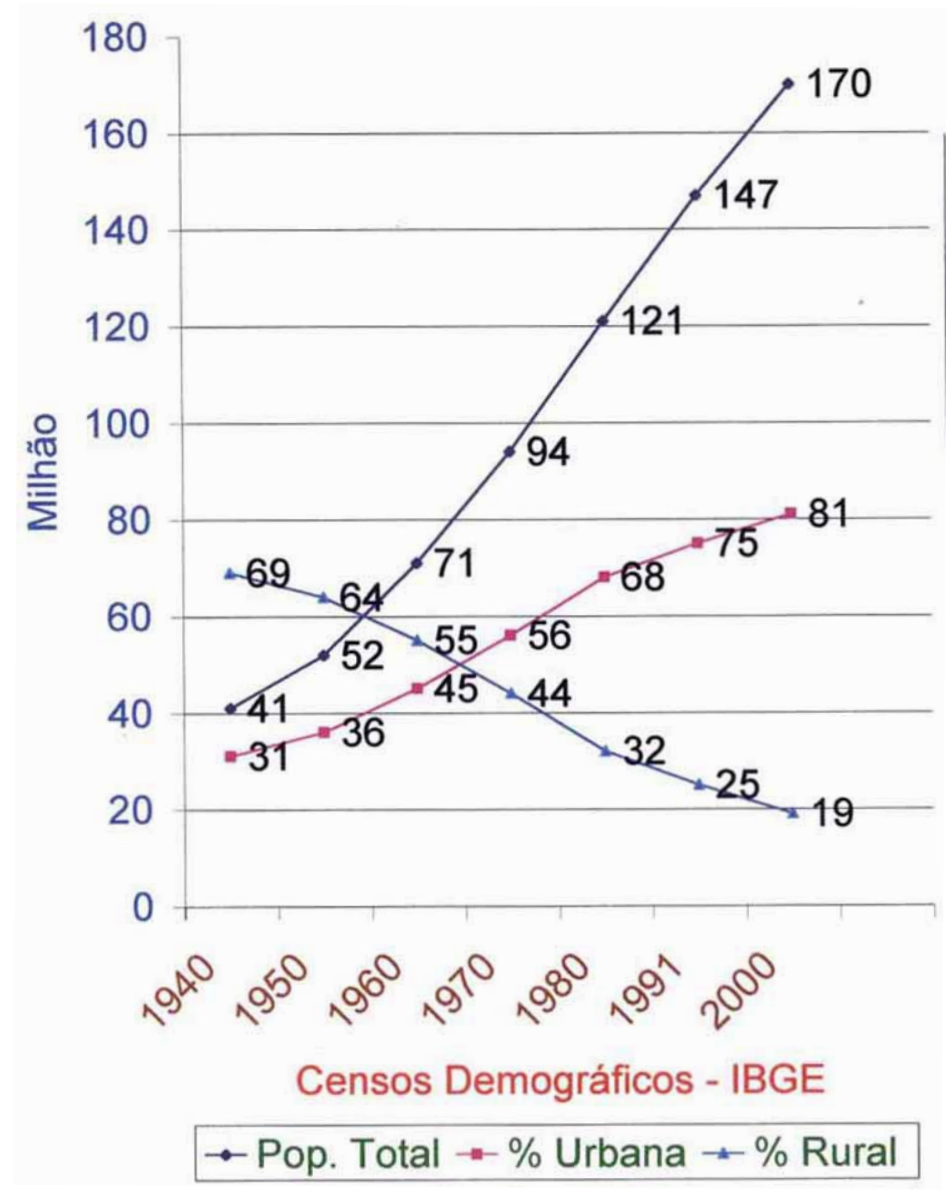

Figura 5. Transformação demográfica no Brasil

Fonte: IBGE, 2000.

Por outro lado, os dados do último censo sanitário (IBGE, 1991) indicam que atualmente, no Brasil, apenas 36\% das empresas estatais de abastecimento de água coletam os esgotos, e apenas $20 \%$ os tratam previamente, antes de lançá-los nos rios e noutros corpos de água. No geral, os dados disponíveis indicam que aproximadamente $90 \%$ do volume de esgotos domésticos coletados nas cidades continuam tendo o mesmo destino, ou seja, rios, outros corpos de água doce, praias e águas litorâneas, sem tratamento prévio. Além disso, estima-se que 75\% dos efluentes industriais também sejam lançados nos rios e outros corpos de água, sem tratamento prévio, e os serviços sanitários não exercem, como tarefa primordial, a coleta e deposição adequada do lixo, principalmente nas cidades. 
Regra geral, a coleta e deposição do lixo que se produz nas cidades brasileiras têm sido tarefas desempenhadas pelas municipalidades, enquanto o abastecimento de água e a coleta dos esgotos são tarefas das empresas estatais.

Lamentavelmente, os cenários vexatórios no meio urbano muito contribuem para que a "crise da água" que se anuncia constituir o flagelo da humanidade ainda nas primeiras décadas deste século XXI, também atingirá o meio rural, à medida que os esgotos domésticos e o lixo produzido são levados das cidades para o campo.

\section{A mudança do velho paradigma do mito da abundância}

Atualmente a sociedade global coloca-nos simultaneamente na complexa situação de cidadãos locais e planetários. Nesse quadro, parte importante de nosso destino passou a ser decidida por forças e interesses que operam em dimensões políticas e sociais cada vez mais distantes do indivíduo que vive, mora e atua em determinada região ou país.

No Brasil, sobre cerca de $90 \%$ do seu território os rios são perenes, isto é, nunca secam, significando que as contribuições dos fluxos subterrâneos são muito importantes nessas áreas. Os dados disponíveis sobre as descargas de base dos nossos rios indicam que a reserva de $112 \mathrm{mil} \mathrm{km}^{3}$ de água subterrânea (Rebouças, 1988) recebe uma recarga anual relativamente importante, mesmo no contexto de clima semi-árido (Rebouças et al., 1999).

A ocorrência da "seca verde" no Nordeste indica que há reposição da umidade do solo da caatinga, ocorrência de descarga de base em todos os rios que compõem as suas 24 unidades de planejamento e recarga dos seus estoques de águas subterrâneas. Este processo de recarga das águas do subsolo resulta certamente da ocorrência de chuvas muito intensas na área.

Os dados disponíveis indicam que a recarga das águas subterrâneas varia entre cerca de $11 \mathrm{~mm} /$ ano no Nordeste semi-árido esculpido no contexto de rochas cristalinas, cujas chuvas são muito irregulares, com altura média anual variando entre 400 e $800 \mathrm{~mm} / \mathrm{ano}$, até mais de $600 \mathrm{~mm} /$ ano no contexto tropical úmido, cuja pluviometria é mais regular, com alturas de chuva variando entre 800 e $2000 \mathrm{~mm} / \mathrm{ano}$. A lâmina infiltrada pode atingir $1000 \mathrm{~mm} /$ ano no contexto de clima amazônico (Rebouças et al., 1999).

Desta forma, o valor médio da taxa de recarga das reservas de água subterrânea do Brasil (112 mil km³) é estimada em 3,4 mil km³/ano. Salienta-se que a utilização de apenas $25 \%$ deste valor já representaria uma disponibilidade de 5 mil $\mathrm{m}^{3}$ /ano por habitante, quando as Nações Unidas estimam que $2 \mathrm{mil} \mathrm{m}^{3}$ / ano/habitante já seria uma taxa de consumo total suficiente para usufruto de boa qualidade de vida, com desenvolvimento sustentado. 
Portanto, torna-se urgente que se pratique uma gestão integrada das águas - captação das chuvas, dos rios, dos aqüíferos e de reuso da água disponível - na unidade hidrográfica de planejamento. Nesta abordagem, todavia, não se deve esquecer que a gestão referida compreende aspectos de oferta e de usos. Assim, torna-se imprescindível que sejam desenvolvidas campanhas permanentes de informação à população em geral de como usar cada vez mais eficientemente a água disponível.

Destaca-se, ainda, que os exemplos oriundos dos países mais desenvolvidos indicam que, como já enfatizado, atualmente se torna cada vez mais importante saber usar a gota d'água disponível do que ostentar a sua abundância.

\section{Classes de oferta de água $\left(\mathrm{m}^{3} / \mathrm{ano} /\right.$ habitante $)$}

A classificação dos países - feita com base na divisão das descargas médias de longo período de seus rios pelas respectivas populações censitárias - é uma maneira de melhor se entender os problemas de distribuição da população e das suas águas.

Os países membros das Nações Unidas (1999) pertencem às seguintes classes:

- muito pobre, dentro da qual se encontra Israel, e compreende 13 países onde se tem menos de $500 \mathrm{~m}^{3} / \mathrm{ano} /$ habitante;

- pobre, classe compreendendo meia dúzia de países onde as descargas médias de água nos seus rios representam entre 500 e $1000 \mathrm{~m}^{3}$ /ano/habitante;

- regular, incluindo 16 países com potenciais entre 1000 e $2000 \mathrm{~m}^{3} / \mathrm{ano} / \mathrm{ha}$ bitante, caso de alguns estados do contexto semi-árido do Nordeste do Brasil;

- suficiente, classe de 32 países com descarga média de longo período dos seus rios variando entre $2 \mathrm{mil} \mathrm{e} 10 \mathrm{mil} \mathrm{m}^{3} / \mathrm{ano} / \mathrm{habitante}$, caso de regiões do Brasil com clima úmido e rios perenes;

- rico, reunindo 27 países com potenciais de água doce em seus rios representando uma oferta entre 10 mil e $100 \mathrm{mil} \mathrm{m}^{3} /$ ano/habitante, caso do Brasil em média;

- muito rico, classe que compreende poucos países com descargas dos rios representando uma oferta de água de mais de $100 \mathrm{mil} \mathrm{m}^{3} /$ ano/habitante, na qual se encontram os estados da região amazônica.

Nesse quadro, os 33 países com taxas inferiores $1000 \mathrm{~m}^{3} /$ ano/habitante são considerados pelas Nações Unidas em condições de "stress de água". A oferta entre 1000 e $2000 \mathrm{~m}^{3}$ /ano/habitante é considerada por ela como suficiente para usufruto de uma boa qualidade de vida com desenvolvimento sustentado.

Com relação aos estados e Distrito Federal do Brasil, essa classificação demonstra que em 21 das 27 unidades da Federação, ou seja, em mais de 77\% 
dos casos brasileiros, as descargas médias de longo período dos rios representam taxas de oferta de água superiores aos $2000 \mathrm{~m}^{3} /$ ano/habitante (Rebouças et al., 1999).

Desta forma, muito embora cerca de $80 \%$ das descargas de água doce dos rios do Brasil estejam na região Amazônica, tem-se entre 1000 e mais de 2000 $\mathrm{m}^{3}$ /ano/habitante até no domínio Semi-árido brasileiro.

Assim, os problemas de escassez periódica de água de beber, de produção de alimentos ou de geração de energia hidrelétrica decorrem fundamentalmente do fato de ter havido um crescimento desordenado das demandas locais de água e energia elétrica, da degradação da qualidade das águas nas cidades ter atingido níveis nunca imaginados, da baixa eficiência das empresas de abastecimento, do grande desperdício da água nas cidades - hábitos de escovar os dentes e fazer a barba com a torneira da pia aberta, banhos muito demorados, uso de bacias sanitárias que gastam 18-20 litros por descarga, quando já existe modelo no mercado que necessita de apenas seis litros, hábito de varrer a calçada, o piso e lavar o carro com a mangueira.

No meio rural do Brasil, tem-se que a área total de solos aptos à irrigação é estimada em 29,6 milhões de hectares - 13,5 milhões de hectares nas áreas de várzeas e 16,1 milhões de hectares em terras altas - o que representa cerca de 3,5\% do território nacional. Entretanto, neste setor, o desperdício de água é ainda mais vexatório, pois aproximadamente $95 \%$ dos quase 3 milhões de hectares que são irrigados atualmente utilizam os métodos menos eficientes, como espalhamento na superfície, aspersão convencional e pivô central (Christofidis, 1999).

\section{Saber usar a água é mais importante do que ostentar sua abundância}

Essencial à vida, a água é um elemento fundamental ao desenvolvimento de diversas atividades humanas, além de constituir componente básico da biomassa, da paisagem e do ambiente. Numerosos são os exemplos de sucesso nos países relativamente mais desenvolvidos, cujos programas de uso cada vez mais eficiente da água disponível foram desenvolvidos a partir da década de 80 .

Tais exemplos mostram que é possível racionalizar o uso da água antes de racioná-la. Para tanto, desenvolvem campanhas permanentes de informação à população em geral, incluindo ensinamentos de como usar a água disponível nos programas das escolas de $1^{\circ}$ e $2^{\circ}$ graus, estimulam a substituição de equipamentos obsoletos por outros mais eficientes, tal como os novos modelos de bacias sanitárias com menor consumo de água por descarga. Em outras palavras, passaram a considerar que se tornava cada vez mais importante saber usar a água de forma eficiente - no meio urbano e rural, principalmente - do que ostentar sua abundância. 
Todavia, a visão de uma exuberante cobertura vegetal e de rios e outros corpos de água que nunca secam sobre mais de 90\% do território do Brasil deu suporte, certamente, à idéia de abundância de água. Como resultado, desenvolveuse uma cultura de tolerância e manipulação dos grandes desperdícios dos usos, com a degradação da sua qualidade atingindo níveis nunca imaginados, tanto nas cidades quanto no campo.

No meio rural, as atividades produtivas mais relevantes são as agrícolas. De fundamental importância à produção agrícola nos meios árido e semi-árido, a irrigação vinha sendo constantemente relegada a um plano inferior nas regiões onde, sob certas condições naturais de chuvas, poderiam ser desenvolvidas culturas naturalmente, com razoável produção.

Entretanto, o custo da terra, aliado ao considerável capital necessário à atividade agrícola, não permite mais que a produção final dependa da ocorrência ou não de um regime de chuvas adequado. Nesse quadro, a irrigação visa corrigir a distribuição natural das chuvas.

Mais de $60 \%$ das derivações dos cursos d'água no Brasil são para fins de irrigação. Assim, pelo fato de a irrigação ser a principal concorrente pelo uso da água disponível numa determinada unidade hidrográfica de planejamento, devese estimular um manejo racional da irrigação e a otimização dos equipamentos utilizados, com a finalidade de tornar o uso da água e da energia elétrica o mais eficiente possível.

Desta forma, devem ser considerados os grandes desperdícios da agricultura irrigada no Brasil, cujos dados disponíveis indicam que em 95\% dos casos são utilizados, como mencionado, métodos menos eficientes.

A estimativa do volume de água desviado para irrigar os 2,87 milhões de hectares no Brasil é da ordem de 33,8 bilhões $\mathrm{m}^{3}$ /ano (Christofidis, 1999). Isto corresponde a uma demanda média de água de cerca de $12 \mathrm{mil} \mathrm{m}^{3} /$ ano por hectare, enquanto os dados apresentados pelo Banco do Nordeste (1999) apontam que os maiores índices de eficiência econômica (US\$ $/ \mathrm{m}^{3}$ de água) pertencem às culturas cuja demanda de água é de apenas $5 \mathrm{mil} \mathrm{m}^{3} /$ ano por hectare. Quando superior a $10 \mathrm{mil} \mathrm{m}^{3}$ /ano por hectare, essa demanda fica na faixa considerada crítica pelo agronegócio das culturas irrigadas no semi-árido, a exemplo de cana de açúcar, arroz, algodão, milho e feijão. A realização destas culturas no Nordeste representa um problema ambiental e uma burrice econômica.

Segundo estudo realizado pela companhia Energética de Minas Gerais (Cemig), se essa irrigação fosse feita de forma racional, aproximadamente $20 \%$ da água e $30 \%$ da energia consumida seriam economizados.

Além disso, o crescimento demográfico brasileiro, associado às transformações pelas quais passou o perfil da economia, refletiu-se de maneira notável sobre 
o uso da água na segunda metade do século XX. Nesse quadro, as atividades agropecuárias evoluíram do nível da subsistência, para se tornar uma atividade multidisciplinar de aplicação de conhecimentos científicos para hidrólogos, agrônomos, veterinários, hidrogeólogos, botânicos, especialistas em tratos culturais e desenvolvimento genético, dentre outros. $\mathrm{O}$ indivíduo analfa-beto não tem mais oportunidades e o uso cada vez mais eficiente da água disponível para a obtenção de uma produtividade agropecuária crescente tornou-se a única alternativa para usufruto de uma vida decente no campo.

A capacidade de suporte econômico das atividades produtivas no campo tem sofrido uma sensível degradação durante as últimas décadas, fomentando o êxodo rural no Brasil. Além disso, o uso de insumos químicos nas atividades agrícolas e pastoris - fertilizantes, pesticidas e herbicidas, principalmente - é cada dia mais intensivo, ocasionando efeitos altamente nocivos à qualidade das águas de consumo no meio rural, sobretudo dos rios e outros mananciais de superfície, e até dos poços rasos.

Os dados disponíveis indicam que o Brasil ocupa o $5^{\circ}$ lugar na lista mundial dos maiores consumidores de pesticidas e herbicidas, utilizando perto de 200 mil ton métricas por ano, cuja aplicação praticamente não é controlada (Rebouças et al., 1999). O mais grave é que estes compostos já são nocivos à saúde em teores de partes por bilhão (ppb), níveis geralmente não alcançados pelos métodos de análise e pessoal disponíveis na maioria dos laboratórios de determinação da qualidade das águas de consumo humano no Brasil.

Outro fator resultante da forma desordenada de uso e ocupação do meio - tanto urbano quanto rural - no país diz respeito ao assoreamento dos corpos d'água - rios e açudes - em níveis muito elevados, e do lixo não-coletado ou depositado de forma inadequada no ambiente, arrastado pelas enxurradas e transportado pelos rios águas abaixo. Desta forma, o meio rural é afetado pelo modelo sanitário dominante nas cidades, tornando caóticas as condições de vida e a qualidade ambiental no campo.

\section{Arcabouço legal-institucional do Brasil é dos mais avançados}

O Brasil ostenta, desde a Constituição Federal de 1988, pelo menos, um arcabouço legal-institucional dos mais avançados do mundo. Além disso, o país tem a Lei Federal no 9433/97, os Planos Estaduais de Recursos Hídricos, as suas leis correlatas e a Lei Federal n ${ }^{\circ}$ 9984/00, que criou a Agência Nacional das Águas (ANA).

O texto da Lei Federal n ${ }^{\circ}$ 9433/97 proclama, com clareza, os cinco princípios básicos praticados hoje em todos os países que avançaram na gestão de seus recursos hídricos: 
- adoção da bacia hidrográfica como unidade de planejamento;

- usos múltiplos da água, quebrando a indesejável hegemonia do setor hidrelétrico sobre os demais;

- reconhecimento da água com um bem finito e vulnerável;

- reconhecimento do valor econômico da água;

- gestão descentralizada e participativa.

Ainda são aspectos relevantes do texto da citada lei, cinco instrumentos essenciais:

- o Plano Nacional de Recursos Hídricos;

- a outorga de direito de uso dos recursos hídricos;

- a cobrança pelo direito de uso da água;

- o enquadramento dos corpos d'água em classes de uso;

- o sistema nacional de informações sobre recursos hídricos.

Esta experiência foi implantada com sucesso comprovado na maioria dos países desenvolvidos. Entretanto, a sua prática ainda representa, no Brasil, um grande desafio ao meio político-administrativo, aos tomadores de decisão, aos técnicos e à sociedade em geral, os quais foram acostumados a considerar a construção de obras extraordinárias como a única alternativa plausível para combater a escassez periódica e o crescimento de demandas futuras de água. Nesse quadro, regra geral, as empresas de água são principalmente tocadoras de obras, sem compromissos com a eficiência no fornecimento da água e a garantia da sua qualidade. Por sua vez, a população em geral não tem demonstrado preocupação em usar de forma eficiente a água disponível.

Além disso, o abastecimento do meio rural tem sido abordado como uma extensão do modelo dominante nas cidades, de tal forma que as metas dos governos - estaduais e federal - consideram a necessidade de fornecimento de água tratada para todos. Desta forma, perde-se de vista o grande alcance do autoabastecimento que poderia ser feito no meio rural, mediante a orientação de como obter água de boa qualidade e de se ter um esgotamento sanitário descente, mediante o uso de fossas sépticas.

Os níveis econômicos do consumo da água que vem sendo impostos pelo agronegócio mundial são de apenas $1 / 3$ daqueles tradicionalmente adotados como demandas de projeto de irrigação no Brasil, significando a possibilidade de não se ter, efetivamente, escassez de água no meio rural.

No Nordeste semi-árido, onde o problema não é de pouca chuva, mas de muita evaporação, o uso cada vez mais eficiente da água disponível para o 
desenvolvimento da cultura, que é remunerada pelo mercado nacional ou mundial, constitui um exemplo de como a população rural poderia atingir um nível de redenção sócio-econômica. Tal fato corrobora, mais uma vez, que é mais importante saber usar a água disponível do que ostentar sua abundância ou escassez.

\section{Conclusões}

A sociedade global coloca-nos simultaneamente na complexa situação de cidadãos locais e planetários. Neste contexto, como colocado exaustivamente, saber usar água disponível com crescente eficiência, é mais importante do que ostentar sua abundância ou escassez. Se não houver uma acentuada diminuição dos grandes desperdícios no uso da água - doméstico, industrial e agrícola - e uma substancial redução dos níveis de degradação da sua qualidade - pelo lançamento de esgotos domésticos e efluentes industriais não-tratados nos rios - o Brasil corre o risco de ser penalizado por suas práticas desleais de mercado, prejudicando o cidadão que mora nas cidades ou no meio rural.

Portanto, o que se precisa neste século XXI que ora se inicia, acima de tudo, é do desenvolvimento de práticas de gestão integrada da água disponível da chuva captada por meio de cisternas, dos rios, do subsolo, da água de reuso não-potável - com o objetivo de produzir cada vez mais - na cidade e no meio rural - utilizando cada vez menos água.

Desta forma, a atividade rural perderia a sua característica de sobrevivência, participaria do mercado e teria como suporte três Es: Ética, Ecologia e Economia do desenvolvimento sustentável. Com o dinheiro assim ganho, o homem do campo poderia obter um fornecimento de água de boa qualidade para o consumo, cuidar da coleta e deposição adequada do seu esgoto e do lixo que produz, ter bons serviços de educação e saúde, além de o conforto da vida moderna.

Referências bibliográficas

BANCO do Nordeste. Orientação à agricultura irrigada no Nordeste. Fortaleza, Frutex, 1999.

CHRISTOFIDIS, D. O uso da irrigação no Brasil (O estado das águas no Brasil 1999). Brasília, ANEEL, SIH; MMA, SRH; MME, 1999, p. 73-82. 334 p.

FAO. Água na agricultura. Roma, Relatório técnico, 1998, 18 p.

IBGE. Censos Demográficos do Brasil. Rio de Janeiro, IBGE, 1991.

IBGE. Censos Demográficos do Brasil. Rio de Janeiro, IBGE, 2000.

ORGANIZAÇÃO DAS NAÇÕES UNIDAS. Classes de países em termos da oferta de água. New York, Relatório técnico, 2000. 
NATIONAL GEOGRAPHIC. World of water. Enough for all? Conservation - Earth Pulse, 2001.

REBOUÇAS, A. C. Groundwater in Brazil. Episodes, v. 11, p 209-214, 1988.

REBOUÇAS, A.C.; BRAGA, B. \& TUNDISI, J.G. Águas doces no Brasil: capital ecológico, uso e conservação. São Paulo, Acad. Bras. Cien./IEA-USP, 1999. 717 p.

SOUZA E SILVA, H.K., FERREIRA ALVES, R.F. O saneamento das águas no Brasil (O estado das águas no Brasil - 1999). Brasília, ANEEL, SIH; MMA, SRH; MME, 1999 , p. 83-101. 334 p.

TELLES, D.A. Água na agricultura e pecuária. In: REBOUÇAS, A.C.; BRAGA, B. \& TUNDISI, J.G. Águas doces no Brasil: capital ecológico, uso e conservação. São Paulo, Acad. Bras. Cien./IEA-USP, 1999. p. 305-38.

UNESCO. Programa hidrológico internacional. Paris, Relatório técnico, 1998, 240 p..

WORLD BANK. Technical Paper, n. 463. Washington, USA, 1999. 45 p.

ABSTRACT - DISCUSSIONS on water resources development generally focus on a variety of technical options, often without considering the potential political repercussions of each option. In this paper are incorporated both technical and political considerations in a tech-political decision-making framework. Water resources development alternatives are then examined to evaluate their priorities for development in rural area of Brazil. If we look at the world around us we see that Brazil enjoys abundant fresh water resources: average per capita renewable water resources of about $35.000 \mathrm{~m}^{3} /$ year in rivers and a per capita of $5.000 \mathrm{~m}^{3} /$ year that could be developed from ground water reservoirs. Nevertheless, the crisis has become apparent as drought; in others, as increased demand; and everywhere, as water pollution. However, fresh water should not appear as constraint in the overall planning process in more than $95 \%$ of states in Brazil, rather realistic development and production targets should be matched to its local water availability. One must began to realize one can no longer follow the philosophy of wastefulness use and discard domestic and industrial sewage into nearby water bodies. For many cases this approach is not merely another alternative, but the only one available.

Aldo da C. Rebouças, professor titular da Universidade de São Paulo, é colaborador no Pós-graduação do Instituto de Geociências, pesquisador do Instituto de Estudos Avançados da USP, consultor da Secretaria Nacional de Recursos Hídricos, Superintendência de Recursos Hídricos da Bahia. 